\title{
Various Aspects of Sex and Gender Bias in Biomedical Research
}

\author{
Jana PLEVKOVA ${ }^{\mathbf{1}}$, Mariana BROZMANOVA ${ }^{\mathbf{1}}$, Jana HARSANYIOVA ${ }^{\mathbf{1}}$, Miroslav \\ STERUSKY ${ }^{1}$, Jan HONETSCHLAGER ${ }^{2}$, Tomas BUDAY ${ }^{1}$
}

${ }^{1}$ Department of Pathophysiology, Comenius University in Bratislava, Jessenius Faculty of Medicine in Martin, Slovak Republic, ${ }^{2}$ Institute of Molecular Genetics of the Czech Academy of Sciences, Prague, Czech Republic, Czech Centre for Phenogenomics BIOCEV, Vestec, Czech Republic

Received March 30, 2020

Accepted October 6, 2020

\section{Summary}

The main role of research in medicine is to provide relevant knowledge which, after successful translation to clinical practice, improves the quality of healthcare. The sex bias which is still present in the majority of research disciplines prefers male subjects despite legislation changes in the US grant agencies and European research programme Horizon 2020. Male subjects (cells, animals) still dominate in preclinical research and it has detrimental consequences for women's health and the quality of science. Opposite bias exists for data obtained mainly in animal models utilizing female subjects (e.g. research in multiple sclerosis, osteoporosis) with skewed outcomes for men affected by these diseases. Either way, scientists are producing results which compromise half of the population. Assumptions that females as cohorts are more variable and another assumption that the oestrous cycle should be tracked in case the females are enrolled in preclinical studies were proven wrong. Variability of male versus female cohorts are comparable and do not only stem from hormonal levels. The widespread prevalence of sex differences in human diseases ultimately requires detailed experiments performed on both sexes, unless the studies are specifically addressing reproduction or sex-related behaviors.

\section{Key words}

Sex bias • Biomedical research • Testosterone • Estrogen

\section{Corresponding author}

T. Buday, Department of Pathophysiology, Jessenius Faculty of Medicine in Martin, Comenius University in Bratislava, Mala Hora 4C, 03601 Martin, Slovak Republic. E-mail: tomas.buday@uniba.sk

\section{Introduction}

Biomedical research has a high value in society. It can provide important information about disease trends and risk factors, outcomes of treatment or public health interventions, and health care. Driven by curiosity, basic research fuels applied science's innovations and connects with clinical studies via translational research (McCormick 2001). Collectively, these forms of research have led to significant discoveries, the development of new therapies, and a remarkable improvement in health care (Bates et al. 1998). The main objective of the research is therefore improved health and quality of life of the population. However, the question of how much are the research outcomes relevant and valid and to what extent do they apply with the same relevance to both men and women remains largely unanswered.

Non-human female mammals and women have been neglected from research for a long time. The reasons why it happened are many and range from assumption that what was found in males is valid also for females, through worry that female oestrous cycle increases heterogeneity of the studied population (Wizemann and Pardue 2001) to misinterpreted idea of "protection" of women from inclusion to the clinical studies where their health can suffer a harm (Keitt et al. 2004). In the past, women of child-bearing age came to be excluded from early clinical trials given birth defects and other negative health outcomes resulting from fetal exposure to certain drugs, which is certainly understandable. But why those practices of exclusion of women of child-bearing age

PHYSIOLOGICAL RESEARCH • ISSN 1802-9973 (online) 
were extended to female cells, tissue cultures and animal models is not known. Perhaps the reason for male-only animal models is convention and convenience. Perhaps it was suggested that males-only may be seen as an easier and possibly cheaper option than using both sexes (Blanchard et al. 1995). Male-only models are very common in many research areas and their use is always adopted by a new-coming generation of scientists even without questioning why this is a male-only sample. The answer would be probably similar to "because we have done it this way for 40 years and it works well".

Although there are some specific areas of interest in which it is entirely appropriate that only one sex should be investigated such as sex-related behaviour or drug interactions with the sex-specific gonadal hormones, it is difficult to justify the exclusion of females or indeed males from many other types of investigation. Without proper sex analysis, we risk claiming a general effect when it only applies to one sex, or that no effect exists whatsoever when there are opposite offsetting effects in the two sexes (Wetherington 2007).

\section{One more trouble for scientists or facing the truth?}

The fact that sex and gender bias does exist in biomedical research has been known for some time (Becker et al. 2005) but one never cared much, unless there is a personal experience. We are a group of scientists involved in research of respiratory physiology and laboratory animal science. In 2015 we published an epidemiological study that showed that patients affected by chronic hypersensitive cough are mainly postmenopausal women (Song et al. 2015). The treatment of this condition remains unknown because, despite tremendous research of mechanisms leading to up-regulation of cough neural pathways, the cause of this particular condition is still not known - therefore we lack causal treatment. The only data about currently known mechanisms of up-regulation of cough neural pathways we had were from animal studies, which were performed exclusively on male guinea pigs for decades. Finding hypersensitive cough syndrome being a female gender issue and not having relevant answers had started a lot of questioning in our research discipline (Plevkova et al. 2017a, Plevkova et al. 2017b). In the scientific literature in largest databases we found only three studies in total, that used female guinea pigs, however, the reason for sex selection criteria was not explained, and the sex of laboratory animals was not taken in consideration during the final data analysis (Forsberg et al. 1988, Ebihara et al. 1996, Ito et al. 2002). Since then, we have developed a model utilizing both sexes of guinea pigs for basic cough research without increased internal variability or decreased power of statistical analysis of combined female and male cohorts (Sterusky et al. 2020).

Similar experiences are published also by other scientists. After decades of research, mostly excluding females/women, researchers began to realize that differences between male and female subjects are found also beyond the reproductive system and that sex is important biological variable in biomedical research (Lee 2018). Very inspiring is the story of Melina Kibbe, who after experiencing considerable sex bias in her research became an advocate of this issue and leads a national fight against sex bias in research in the United States (Yoon et al. 2014).

\section{Gender and sex in research terminology}

Our analysis of sex/gender-related bias in scientific literature has shown that the terms "sex" and "gender" are not used correctly by many authors. Even the English language is not always the first language of authors publishing their results in international journals, the language and expression accuracy should be required. Sex is, according to medical databases, classification of studied subjects as male or female according to their reproductive organs and functions assigned by sets of chromosomes. Sex is related to reproductive organs anatomy and physiology. Gender is a person's selfrepresentation as male or female or how that person is responded to by social institutions. It is shaped by environment and experience and refers to socio-culturally constructed norms and identities (Lee 2018, Beery 2018).

\section{Consequences of sex/gender bias}

Paradoxically - protection of women's health by not recruiting them to the clinical studies and neglect of female non-human subjects in basic research has led to the negative impact on women's health. There is substantial evidence that sex bias in research is responsible for e.g. failure of designed treatment that works perfectly well for men, but does not work for women. The reported rate of drugs adverse effects is also higher for women, just because these substances were developed and tested via the entire research process on 
male subjects (Heinrich 2001). A recent paper by Lee (Lee 2018) reports that during the time period from 1997 to 2000 , ten prescriptions drugs were withdrawn from the market by the US Food and Drug Administration because they represented greater health risk for women. Four of these ten drugs that were developed and prescribed to treat diseases both in men and women and belonged to the general categories of antihistamines, cardiovascular and gastrointestinal therapies caused severe, lifethreatening arrhythmia Torsade de Pointes, mostly in women (Heinrich 2001). It was thought that the reason was a higher rate of prescription of a particular medication to women, however detailed analysis confirmed that drugs that have been withdrawn were prescribed to women and men equally (Hughes 2007) but had more detrimental effects on women. Of course, those adverse effects could be caused by wrong prescription or improper use, however potential sex differences in physiology and pharmacology of these drugs cannot be ignored.

By avoiding both-sexes studies and performing experiments on male-only or female-only animal models basic scientists are limiting their responsibilities to the half of the human population (Mogil and Chanda 2005), e.g. autoimmune diseases such as Grave's disease, systemic lupus and Hashimoto's thyroiditis affect predominantly women by 7 to $10: 1$ ratio, but this ratio is opposite for other autoimmune diseases such as ankylosing spondylitis, Reiter or Goodpasture syndromes (Fish 2008). These diseases should be definitely studied concerning sex as one of the determining factors, however, Beery and Zucker (2011) report that in their analysis of articles published in 2011 in journals in the field of immunity and immunology failed to specify the sex of studied subjects in $75 \%$ of cases.

\section{Male and female bias in research}

According to the outcomes of multiple studies in different fields of research one sex-only studies produce skewed data. Results from male-only versus female-only studies differ considerably e.g. in studies assessing response to medication. It is known that low dose of aspirin has different preventive effects in women and men and that drug such as zolpidem used to treat insomnia requires different dosing in women and men (Soldin and Mattison 2009). Sex differences are found in the outcomes of studies of neurological, cardiovascular and autoimmune disorders (Fish 2008).

\section{Male bias}

Is modern research at all its levels from bench to the bedside sufficiently attentive to female subjects? Analysis of scientific papers published in 10 major biological disciplines confirmed previously recognized strong male sex bias (Sechzer et al. 1994, Blanchard et al. 1995). The study by Beery and Zucker - analysis of scientific articles published in 2011 - showed that male bias is still present in 8 out of 10 surveyed fields including neurosciences, physiology, pharmacology, endocrinology, zoology and to lesser extent behavioural physiology. The ratio of articles reporting on males-only samples versus females-only samples was most skewed for neuroscience (5.5:1), pharmacology (5:1) and physiology (3.7:1) (Beery and Zucker 2011). Similar bias towards the use of male subjects was found in laboratory research of pain, diabetes, cardiovascular diseases and surgical methods (Yoon et al. 2014, Flórez-Vargas et al. 2016). A recent analysis from 2017 in neuroscience for example points towards decreased rate of omissions of subjects sex reporting, however, the proportion of maleonly rodent studies has increased while analysis by subjects sex remains infrequent (Will et al. 2017).

The consequences of male-only studies were already mentioned. The higher rate of adverse effects of medication affecting women and withdrawal of drugs from the market due to their detrimental effects on women's health after they have been claimed effective and safe based on research speaks for itself.

\section{Female bias}

Logically, if the disease affects both men and women, while the pathogenic process or drug efficacy is studied mainly in male animal models or men in clinical studies (what is most common scenario seen in the sexbiased research) - the data will be skewed and less valid (if not completely invalid) for women. Does the opposite situation exist? Does the female bias lead to the production of skewed data for men?

A female bias was identified in the field of reproductive physiology where females were used 1.6 times more often than males and immunology where the ratio is $2.2: 1.94 \%$ of these reported animals were rodents - mice or rats (Beery and Zucker 2011). The question is whether should the study population (experimental research on animal models, or cell lines) reflect epidemiological data regarding the prevalence and 
distribution of the diseases between men and women or should it be equally attentive to both sexes?

An interesting example is multiple sclerosis (MS). MS is a lifelong disease affecting individuals in young to middle adulthood, typically with the dysregulated autoimmune reaction towards neural tissue leading to progressive demyelination. MS affects women approximately three times more than men, thus resulting in less attention to men with MS (Rahn et al. 2014). There are recognized sex differences in MS onset and clinical course which is the consequence of natural sex/gender dimorphism. What is not natural is a less effective treatment of MS, which is not only caused by a disease dimorphism but also by outcomes from basic research of MS and early-stage pharmacological studies in MS because they are conducted mainly on models utilizing female sex. Based on detailed studies researchers conclude that e.g. female rodents are superior to males for the study of neuropathic pain-like behaviors associated with MS (Rahn et al. 2014). It makes sense if the disease affects predominantly women to use female animal models, but here the scenario repeats but in the opposite direction. Little knowledge is worse than no knowledge and male patients with MS are treated and managed less effectively e.g. differences in safety issues during fingolimod therapy in subjects with MS were detected. In this cohort, female subjects were experiencing mainly infections as an adverse effect of the drug while men were facing liver damage with an elevation of transaminase markers in the serum (Manni et al. 2017).

Another brilliant example is osteoporosis. Osteoporosis was considered as solely women's disease. Clinicians believe that the decline in bone density and its complications solely affect postmenopausal women, however, osteoporosis and its complications affect both genders but at different ages and rates. Osteoporosis is four times more common in women than in men, but some evidence indicates that men tend to have more osteoporosis-related complications (Alswat 2017). Most animal models have utilized females and osteoporosis in males has been largely ignored (Simon Turner 2001, Komori 2015). The consequences of this bias are less known pathogenic mechanisms, insufficient screening schemes and very often a failure in the prevention and/or treatment. It was found that antiosteoporotic drugs effective in women do not have the same effect in men (Schwarz et al. 2011, Kaufman et al. 2013), and in fact, majority of such drugs have been tested on female animal models. From a clinical perspective, a major limitation is the lack of studies about osteoporosis in men. Further and expanded studies of osteoporosis in men across all areas are needed to address this limitation.

\section{Sexual/gender dimorphisms at its various levels}

Author of a comprehensive book "Principles of Gender-specific Medicine" Marianne Legato points to the need of accepting gender as a critical and determining factor in understanding human biology, the nature of the human disease and therapy (Legato 2010). It is necessary to understand for basic science and in general, for all research community, that sex differences are not related only to the reproductive system but they do exist beyond it in every single body system (central and peripheral nervous system, gastrointestinal, respiratory, cardiovascular, endocrine etc.) and they are also relevant for majority of human diseases.

Dimorphism is already present at the cellular level. The sex of cells in the cell cultures in vitro matters. Just to set some examples - female and male cells respond differently to stressors, they have different responses in processes of proliferation, differentiation and apoptosis (Penaloza et al. 2009). These intrinsic differences are hormone-independent but can be further modulated by the presence of hormones. For example, male neurons (XY neurons) are more sensitive to the stress caused by exposure to reactive oxygen species and excitatory neuromediators while female neurons (XX neurons) are more sensitive to stimuli influencing apoptosis (Du et al. 2014). Sex of the cells used in the study is not sufficiently reported in scientific papers. Only roughly $23 \%$ of articles in top cardiovascular journals reported cell sex (Taylor et al. 2011). Among these studies, more than $60 \%$ used male cells and none exclusively used female cells. This bias is present also in other research disciplines using cell cultures (Lee 2018). Surprisingly, sex of the cells is also ignored by laboratories providing cell lineages for scientific use - the cells are sold without sex specification (Park et al. 2015).

Sexual dimorphism was detected even at the level of genetic information - more than 23000 transcripts of mouse genes exhibit male versus female differences ranging from $14 \%$ in the CNS to $70 \%$ in the liver with intermediate values in adipose tissue and muscles (Yang et al. 2006). Many of these genes are involved in the pathogenesis of common diseases, in 
which susceptibility is sex-biased and single-sex studies cannot provide a complete understanding of how these genes e.g. interact with epigenetic factors or how they are modulated by internal factors of the organism (Pessin and Marts 2005).

\section{Effect of legislation changes, grant agencies and editorial offices policies}

Considerable gender bias in clinical and also basic laboratory research and its impact on women's health has been recognized in the past and led to certain legislative changes in funding agencies. National Institute of Health issued a Revitalization Act in 1993 requiring recruitment female participants in federally supported clinical trials in sufficient numbers to enable a reliable analysis of differences among groups (Klinge and Wiesemann 2010). In 1999 the National Academy of Sciences in the US established a committee that consisted of experts in different fields to evaluate and determine the sex/gender differences and their position in research. Their report clearly stated that sex is an important variable and should be considered in designing research projects (National Institutes of Health 2001). Similarly, the European Union programme was issued for researchers giving them a tool and good practical examples regarding enrolment of women and non-human female mammal subjects to the research protocols (Klinge and Wiesemann 2010). Even though these legislation changes did exist, realistically, a significant move towards research protocols that would conduct e.g. basic science studies on both sexes was not registered (Sandberg and Ji 2012).

This is documented in the survey from 2011. Analysis of research papers have shown interesting and very promising trends regarding the change in sex distribution in animal and human studies, since 1909 for animal studies and since 1949 for human studies (Beery and Zucker 2011). While the proportion of studies with unspecified sex of participants decreased to zero in 1999, the percentage of studies on both sexes of human participants is increasing to more than $60 \%$ from roughly $30 \%$ in 1949 , which is an excellent shift for human studies. However, the male-only non-human studies (laboratory research on animals, tissues or cell lines) still take $60 \%$ in average, with still having around $20 \%$ of studies where the sex of subjects is either unspecified or specified but not taken into account during data analysis. In the graphs describing trends in the rate of one sex-only studies versus both-sexes studies after implementation of mentioned changes in grant agency policies, it is clear that these legislative changes were effective enough for human studies. Both sexes human studies are the dominant type of studies in this category, however, animal studies were not influenced at all. Males were still dominating in preclinical and basic research studies.

Similar data are available in an article published in 2010 (Zucker and Beery 2010) in which the authors analysed the use of female animal subjects in studies for diseases such as anxiety, depression, thyroiditis, epilepsy, multiple sclerosis, obesity, hypertension, stroke and pain. This study showed that the proportion of female and male rodents in these studies was not equal, female animals were severely under-represented even in diseases which are commonly more prevalent in women. Diseases such depression or anxiety are twice as likely to be diagnosed in women, but fewer than $45 \%$ of animal models used female subjects to investigate hypotheses postulated about these particular disease conditions (Zucker and Beery 2010). One might suggest that perhaps this report is 10 years old, more recent reports e.g. from 2016 are showing that situation has not improved much (Zakiniaeiz et al. 2016, Kong et al. 2016).

This is a little bit disturbing because the clinical studies are designed and based on the results of basic and preclinical research. Much of our understanding of disease mechanisms and treatment possibilities came from non-human studies performed either on animal models or cell cultures. If these studies are biased from the very beginning, planning, designing, funding and also final realization and analysis of data from clinical studies will be influenced by this bias. Therefore, sex should be considered as an important variable even at the level of basic research.

\section{Gonadal hormones as a problem in animal research}

A title of this paragraph has been changed from "ovarian hormones" to gonadal hormones, because of the assumption that only ovarian hormones cause variability and therefore disqualify female cohorts as reliable samples are not valid any longer. For a long time, there was an assumption, that circulating ovarian hormones during oestrous cycle make the data from female animals more variable than data from males. This biases not only the subject selection but also the experimental design, peer review of grants and manuscripts when female 
animals are recruited to the study. It is also important to note that sex differences are in any case, incompletely explained by the action of sex hormones alone (Cahill 2006). Therefore why blaming them and using them as an excuse for not enrolling female subjects to research projects?

Whereas there are indeed examples of greater inter-subject variability among female rats in some traits, there are also examples of lack of oestrous cycle-based fluctuations in investigated traits and finally there also examples of greater inter-subject variability in male rats and males of other species (Hughes 2007).

In female rodent subjects, similarly in humans, levels of circulating ovarian hormones fluctuate during the oestrous cycle, which typically lasts around 4-5 days. Therefore, there are phases characterized by high and low concentrations of oestrogen and progesterone (proestrus, oestrus, metestrus phases). This means that in your study cohort you very likely have mice or rats' female subjects with fourfold differences in their hormonal levels. Presuming that these differences would lead to variable, un-interpretable data, scientists chose to avoid this issue altogether and exclude female animals from the research (Wald and $\mathrm{Wu}$ 2010). This seemed to be a very practical choice and in years it became dogma.

Sex hormones are "scary" even for the researchers in clinical research. Some authors advocate for separate women cohort sub-groups - population of women on hormonal contraceptives. Of course, this is particularly important mainly in the brain and behavioural studies (Becker et al. 2005).

Attempts to reduce the influence of ovarian hormones in animal research have included testing only during diestrus phase of the cycle, when oestrogen and progesterone levels are low (Mora et al. 1996) or simply tracking the cycles by evaluation of hormonal levels from blood or vaginal cytometry. In case of variables fully dependent on oestrous cycle a study requires four times more female subjects (in particular cycle phase) to minimize the effect of hormonal levels on given variable. However, these procedures, which increase the cost of the research and are not in alignment with the $3 \mathrm{R}$ are now not necessary in all types of research. Increased costs of such research due to the increased number of animals should be compared to the benefits such study can offer - and it is the highest accuracy of the data. Also, the animal welfare bodies should clearly state their pros versus cons to such approach.

In this aspect, consideration of the impact of oestrous cyclic events on traits which are evaluated in the research is critically important, given the differences between the rodent oestrous cycle and human menstrual cycle. This is of particular interest in behavioural studies, e.g. although the changes in levels of sex hormones may follow a similar pattern in both types of the cycle, the expression of female sexual behaviour in rodents is rigidly tied to the onset of oestrus, whereas women are sexually receptive at any stage of the menstrual cycle (Eliot and Richardson 2016).

Several new genetic and epigenetic animal models have increased translational validity, e.g. it is possible to prepare a model that represents human ovarian failure and menopause using Foxl2 deficient mice with accelerated rates of decline in ovarian reserve. Another frequent approach to eliminate the effect of sex hormones is a genetically modified animal that lacks a specific steroid receptor, e.g. ER $\alpha$ knockout mice. However, this is not the best approach since oestrogen effects are not exclusively mediated only by ER $\alpha$, but it also utilizes alternative signalling pathways (Phillips and Roth 2019).

In 2014, for the first time in the long-lasting era of what we call modern research in meta-analysis of 300 scientific articles that used rodents as a study subjects, it was found that variability in an array of physiological, cellular, hormonal and behavioural data collected from female rodents, regardless of oestrous cycle, did not vary more than the data from males, and in some parameters, the data from males varied even more than data from females (Prendergast et al. 2002, Becker et al. 2005). These studies also indicate that it is not necessary to track the stage of the oestrous cycle in research unless the primary role of the research is not related to reproduction or effect of substances which primary target is the level of sex hormones.

From the perspective of tracking the hormonal levels no one ever complained about the variability of male cohorts potentially influenced by testosterone fluctuation. There might be an argument for monitoring of testosterone in some investigations if the male animals are not tested at the same time of the day, as changes in concentration of testosterone in rodent vary rhythmically in a trimonal fashion during a 24-hour period (Mock and Frankel 1978). Another important source of testosterone fluctuation and possibly variability in males in rodents is housing type.

Rodents are usually group-housed. Grouphoused males fight opposed to females, they establish 
dominance hierarchies in which the dominant male monitors and defends the entire cage space, frequently attacks subordinate males, activating sympathetic pathways and stress axis increasing level of cortisol in subordinates. It can be so significant that it causes analgesia in subordinate males (Shansky 2019). The dominant male has five times higher concentration of testosterone than subordinates on average, therefore the data from male subjects could be influenced by hormonal status as well. Testosterone is known to be a powerful neuromediator, and it also influences multiple body functions (McEwen and Milner 2017). So here applies the hormone-based variability in males no one ever complained about so far. While the levels of sex hormones as a source of variability in females are influenced by the oestrous cycle, the level of testosterone is influenced by natural $24 \mathrm{~h}$ fluctuation and housing conditions in males. Although sex hormones influence multiple body functions, they do not disqualify male or female cohorts from studies and both cohorts have comparable variability.

Both American and Canadian research funding agencies require from 2016 both-sex studies and although the policies are based on reasonable background, there were worries about increasing costs of the research caused by an increased number of animals, which will be required, increased costs and time-consuming procedures of their hormonal cycles tracking etc. Because according to the data obtained from studies utilizing both mice and rats and their comprehensive meta-analysis, both male and female samples are equally variable, there is no justification for requiring oestrous cycle assessment (or statistical power to evaluate oestrous effects) in females without demanding evaluation of testosterone (or statistical power to account for cage dominance effects) in males. This is not related to the studies of reproduction where, of course, the role of hormones is the key factor.

If the degree of variability in male samples is acceptable for scientific purposes, so is the degree of variability of female samples if female cohorts should be deemed acceptable in research.

\section{Arguments from laboratory animal science}

Laboratory animal science develops as quickly as the research itself. It is believed that valid and reliable data can be only obtained from laboratory animals with the high-quality standards, therefore attention is given to the animal care - housing conditions, nutrition, hydration, light-dark cycles preservation, enrichment, microbiological and veterinary controls and many more.

3R principles in animal care and use suggest reduction, replacement and refinement in laboratory research for the sake of animal welfare. Performing experiments now on both sexes requires more subjects to be tested, which is against the main principles of $3 R$ because they suggest using as few animals as possible to obtain valid and statistically powerful data. Regarding the number of animals, there were voices pointing towards the excessively increased count of female animals in reproductive age if it will be confirmed that studied trait/parameter is influenced by the oestrous cycle. In that case, researchers may need four times more female animals as female rodents have a four-stages ovarian cycle (Becker et al. 2005). Based on recent analysis, tracking of hormonal cycles, in general, is not necessary as we said before unless the studied parameter is directly influenced by the stage of the cycle. This is related to the disciplines studying reproduction or behavioural studies (Becker et al. 2005).

Some authorities of animal welfare bodies may argue, that using more animals is not ethical and not necessary, however, we cannot ignore substantial evidence pointing towards sex as an important variable. Therefore, careful planning of experimental design and validating results by replication is a prerequisite of excellent science.

Another argument will mention financial burden - more money spent on animals, chemicals, more time spent performing experiments etc. From the quick look into this process one may see this reason not to use as many animals as recommended to prevent money waste, but including both sexes at early stages of research will save money and time than testing sex differences in more expensive and lengthy clinical trials. It also prevents even more costly and dangerous situations such as withdrawing drugs after marketing due to unforeseen sex differences in adverse effects. Analysis of sex differences in basic research is likely to save more money in the long-term perspective (Rich-Edwards et al. 2018, Lee 2018).

Some authors mention problems with the experimental procedures in e.g. behavioural studies in case both male and female rodents are enrolled. The possibility that if male rodents are tested in experimental apparatus recently used for testing females, their behaviour might be influenced by the presence of 
olfactory stimuli left by the female exists. This is because male mice have been shown to discriminate between male and female odours and to exhibit behavioural changes following exposure to female odours within $24 \mathrm{~h}$ even after proper cleaning of the apparatus (Kavaliers et al. 2003). Again, to address this issue, a blueprint of the experiment is necessary to avoid such a coincidence.

A sex-informed and gender-informed perspective is essential to increase accuracy and to expand the relevance of research is becoming a new research culture. Investigators who wish to include both sexes in their studies are faced with a number of methodological questions, including issues of motivation, subject selection, sample size, data collection, analysis and interpretation. Inclusion of both sexes is more nuanced than deciding that the sample should be equally divided by sex. Also, sex-specific age incidence of disease, reproductive stage, reproductive cycle and environment need to be considered to optimize validity, generalizability and efficacy of study sample. RichEdwards et al. in recent paper reviewed principles, which should be followed in case that investigators want to include both sexes to their study (Rich-Edwards et al. 2018). Authors of this review recommend considering sex-specific age prevalence of disease to maximize statistical power, consider reproductive stages and cycles, particularly where they may modify the impact of the main exposure being investigated. For basic and preclinical studies, review options for classical gonadectomy, knockouts, or four-core genotype experiments.

Researchers are also encouraged to seek the guidance of experts in animal care \& use and animal welfare bodies to address accurately the sex-related questions. An important contribution is also available from the experts in biostatistics who can help with the calculation of appropriate sample size and the number of experimental/control groups per experiment according to the expected power of the experiment, confidence level and confidence intervals of expected results. Free online sample calculators are not always sufficient to calculate sample size properly for more groups and more variables.

According to the ARRIVE guidelines (Kilkenny et al. 2010), in reporting an experiment it is necessary to provide details of the animals used, including species, strain, sex, developmental stage, age and weight. To adhere to the principles of precision in science it is also necessary to specify the total number of animals used in each experiment, and the number of animals in each experimental group and also explain how the number of animals was calculated and provision of details of any sample size calculation that was used (www.3rsreduction.co.uk/html/6_power_and_sample_size.html). Calculation of sample size is one of the important components of the design of any research including animal studies. If a researcher selects a smaller number of animals it may lead to missing of any significant difference even if it exists in population and if a greater number of animals is selected then it may lead to unnecessary wastage of resources and may lead to ethical issues - have you ever thought about fate of female animals which are born in an animal breeding facility, but are neither used for further reproduction nor research purposes?

\section{Recent legislation changes and scientists themselves advocate sex/gender equality in research}

Even after decades of effort to integrate sex/gender in biomedical research, the change has been slow. Most recently issued policies of funding agencies such as National Institutes of Health (NIH) and Canadian Institutes of Health Research (CIHR) are stricter when it comes to review of basic research projects, noting sex bias has negative consequences. Similarly, Horizon 2020 which is the largest Research and Innovation Programme in the European Union supports the sex/gender equality in research. A position paper published by European experts and recommendations of NIH and CIHR encourages and guides scientists to use both male and female animal research subjects and consideration of sex as a biological variable (Clayton and Collins 2014). Researchers are required to use both sexes of laboratory animals, or clearly state and defend by reasonable arguments, why they are using male-only or female-only animals in their study.

The future will answer the question of how effective these policies really are and what changes we will observe in the consideration of sex in biomedical research. Scientists who are willing to follow these rules in their grant applications and research reporting can educate themselves in online training modules and also get advice from the documents issued by abovementioned authorities online. Recent policy changes and recommendations even paraphrasing crucial parts of documents were extensively reviewed elsewhere (Lee 2018). 


\section{Conclusions}

To change the state-of-the-art, it is necessary to change the attitude and approach of high-quality scientific journals, which publish research results. Journal editors can facilitate innovation through changes in journal policies. In the past, there were only a few journals, whose policies considered this sex/gender issue. For example, Journal of National Cancer Institute in the instruction for authors states "clinical and epidemiological studies should be analysed to see an effect of sex and if there is no effect it should be stated in the results" (Wald and Wu 2010, Beery and Zucker 2011).

Nowadays, prestigious, high-quality journals already in their "instructions for authors" require authors to clearly report the sex/gender of the research subjects including cells, animal models and human, and to analyse data by sex/gender. SAGER (Sex and Gender Equity in Research) initiative of European Association of Science Editors is changing the global standards and quality of reported research by guidelines which needs to be followed in case scientists want to adopt more systemic approach to the sex/gender reporting (De Castro et al. 2016).

\section{Conflict of Interest}

There is no conflict of interest.

\section{Acknowledgements}

This publication was supported by Scientific Grant of Ministry of Education, Science, Research and Sport (VEGA) No. 1/0260/18.

\section{References}

ALSWAT KA: Gender disparities in osteoporosis. J Clin Med Res 9: 382-387, 2017. https://doi.org/10.14740/jocmr2970w BATES DW, LEAPE LL, CULLEN DJ, LAIRD N, PETERSEN LA, TEICH JM, BURDICK E, HICKEY M, KLEEFIELD S, SHEA B, VANDER VLIET M, SEGER DL: Effect of computerized physician order entry and a team intervention on prevention of serious medication errors. JAMA 280: 1311-1316, 1998. https://doi.org/10.1001/jama.280.15.1311

BECKER JB, ARNOLD AP, BERKLEY KJ, BLAUSTEIN JD, ECKEL LA, HAMPSON E, HERMAN JP, MARTS S, SADEE W, STEINER M, TAYLOR J, YOUNG E: Strategies and methods for research on sex differences in brain and behavior. Endocrinology 146: 1650-1673, 2005. https://doi.org/10.1210/en.2004-1142

BEERY AK: Inclusion of females does not increase variability in rodent research studies. Curr Opin Behav Sci 23 : 143-149, 2018. https://doi.org/10.1016/j.cobeha.2018.06.016

BEERY AK, ZUCKER I: Sex bias in neuroscience and biomedical research. Neurosci Biobehav Rev 35: 565-572, 2011. https://doi.org/10.1016/j.neubiorev.2010.07.002

BLANCHARD DC, GRIEBEL G, BLANCHARD RJ: Gender bias in the preclinical psychopharmacology of anxiety: male models for (predominantly) female disorders. J Psychopharmacol (Oxf) 9: 79-82, 1995. https://doi.org/10.1177/026988119500900201

CAHILL L: Why sex matters for neuroscience. Nat Rev Neurosci 7: 477-484, 2006. https://doi.org/10.1038/nrn1909

CLAYTON JA, COLLINS FS: Policy: NIH to balance sex in cell and animal studies. Nature 509: 282-283, 2014. https://doi.org/10.1038/509282a

DE CASTRO P, HEIDARI S, BABOR TF: Sex And Gender Equity in Research (SAGER): reporting guidelines as a framework of innovation for an equitable approach to gender medicine. Commentary. Ann Ist Super Sanita 52: 154-157, 2016. https://doi.org/10.4415/ANN_16 $02 \quad 05$

DU S, ITOH N, ASKARINAM S, HILL H, ARNOLD AP, VOSKUHL RR: XY sex chromosome complement, compared with $\mathrm{XX}$, in the CNS confers greater neurodegeneration during experimental autoimmune encephalomyelitis. Proc Natl Acad Sci U S A 111: 2806-2811, 2014. https://doi.org/10.1073/pnas.1307091111

EBIHARA T, SEKIZAWA K, OHRUI T, NAKAZAWA H, SASAKI H: Angiotensin-converting enzyme inhibitor and danazol increase sensitivity of cough reflex in female guinea pigs. Am J Respir Crit Care Med 153: 812-819, 1996. https://doi.org/10.1164/ajrccm.153.2.8564137 
ELIOT L, RICHARDSON SS: Sex in context: Limitations of animal studies for addressing human sex/gender neurobehavioral health disparities. J Neurosci 36: 11823-11830, 2016. https://doi.org/10.1523/JNEUROSCI.1391-16.2016

FISH EN: The X-files in immunity: sex-based differences predispose immune responses. Nat Rev Immunol 8: 737-744, 2008. https://doi.org/10.1038/nri2394

FLÓREZ-VARGAS O, BRASS A, KARYSTIANIS G, BRAMHALL M, STEVENS R, CRUICKSHANK S, NENADIC G: Bias in the reporting of sex and age in biomedical research on mouse models. eLife 5: e13615, 2016. https://doi.org/10.7554/eLife.13615

FORSBERG K, KARLSSON JA, THEODORSSON E, LUNDBERG JM, PERSSON CG: Cough and bronchoconstriction mediated by capsaicin-sensitive sensory neurons in the guinea-pig. Pulm Pharmacol 1: 33-39, 1988. https://doi.org/10.1016/0952-0600(88)90008-7

HEINRICH J: U.S. GAO - Drug safety: Most drugs withdrawn in recent years had greater health risks for women. Available at: https://www.gao.gov/products/GAO-01-286R [Accessed January 23, 2020], 2001.

HUGHES RN: Sex does matter: comments on the prevalence of male-only investigations of drug effects on rodent behaviour. Behav Pharmacol 18: 583-589, 2007. https://doi.org/10.1097/FBP.0b013e3282eff0e8

ITO N, SHIOYA T, WATANABE A, SANO M, SASAKI M, MIURA M: Mechanism of the antitussive effect of azelastine in guinea pigs. Arzneimittelforschung 52: 441-447, 2002. https://doi.org/10.1055/s-0031-1299912

KAUFMAN J-M, REGINSTER J-Y, BOONEN S, BRANDI ML, COOPER C, DERE W, DEVOGELAER J-P, DIEZPEREZ A, KANIS JA, MCCLOSKEY E, MITLAK B, ORWOLL E, RINGE JD, WERYHA G, RIZZOLI R: Treatment of osteoporosis in men. Bone 53: 134-144, 2013. https://doi.org/10.1016/j.bone.2012.11.018

KAVALIERS M, COLWELL DD, BRAUN WJ, CHOLERIS E: Brief exposure to the odour of a parasitized male alters the subsequent mate odour responses of female mice. Anim Behav 65: 59-68, 2003. https://doi.org/10.1006/anbe.2002.2043

KEITT SK, FAGAN TF, MARTS SA: Understanding sex differences in environmental health: a thought leaders' roundtable. Environ Health Perspect 112: 604-609, 2004. https://doi.org/10.1289/ehp.6714

KILKENNY C, BROWNE WJ, CUTHILL IC, EMERSON M, ALTMAN DG: Improving bioscience research reporting: the ARRIVE guidelines for reporting animal research. PLoS Biol 8: e1000412, 2010. https://doi.org/10.1371/journal.pbio.1000412

KLINGE GT, WIESEMANN C: Sex and Gender in Biomedicine: Theories, Methodologies, Results. Universitätsverlag Göttingen, Göttingen, Germany, 2010, 128 p. https://doi.org/10.17875/gup2010-394

KOMORI T: Animal models for osteoporosis. Eur J Pharmacol 759: 287-294, 2015. https://doi.org/10.1016/j.ejphar.2015.03.028

KONG BY, HAUGH IM, SCHLOSSER BJ, GETSIOS S, PALLER AS: Mind the gap: Sex bias in basic skin research. J Invest Dermatol 136: 12-14, 2016. https://doi.org/10.1038/JID.2015.298

LEE SK: Sex as an important biological variable in biomedical research. BMB Rep 51: 167-173, 2018. https://doi.org/10.5483/BMBRep.2018.51.4.034

LEGATO MJ: The skewed sex distribution in affective disorders--a diagnostic, social, or biological problem? Prog Brain Res 186: 159-166, 2010. https://doi.org/10.1016/B978-0-444-53630-3.00010-5

MANNI A, DIRENZO V, IAFFALDANO A, DI LECCE V, TORTORELLA C, ZOCCOLELLA S, IAFFALDANO P, TROJANO M, PAOLICELLI D: Gender differences in safety issues during fingolimod therapy: Evidence from a real-life Relapsing Multiple Sclerosis cohort. Brain Behav 7: e00804, 2017. https://doi.org/10.1002/brb3.804

MCCORMICK J: Scientific medicine: the contribution of science to medicine. Occas Pap R Coll Gen Pract 36: 3-6, 2001.

MCEWEN BS, MILNER TA: Understanding the broad influence of sex hormones and sex differences in the brain: sex hormones affect the whole brain. J Neurosci Res 95: 24-39, 2017. https://doi.org/10.1002/jnr.23809

MOCK EJ, FRANKEL AI: A Shifting circannual rhythm in serum testosterone concentration in male laboratory rats. Biol Reprod 19: 927-930, 1978. https://doi.org/10.1095/biolreprod19.4.927

MOGIL JS, CHANDA ML: The case for the inclusion of female subjects in basic science studies of pain. Pain 117: 1-5, 2005. https://doi.org/10.1016/j.pain.2005.06.020 
MORA S, DUSSAUBAT N, DÍAZ-VÉLIZ G: Effects of the estrous cycle and ovarian hormones on behavioral indices of anxiety in female rats. Psychoneuroendocrinology 21: 609-620, 1996. https://doi.org/10.1016/S03064530(96)00015-7

NATIONAL INSTITUTES OF HEALTH: NOT-OD-02-001: AMENDMENT: NIH POLICY AND GUIDELINES ON THE INCLUSION OF WOMEN AND MINORITIES AS SUBJECTS IN CLINICAL RESEARCH OCTOBER, 2001. Available at: https://grants.nih.gov/grants/guide/notice-files/NOT-OD-02-001.html [Accessed January 26, 2020], 2001.

PARK M-N, PARK JH, PAIK HY, LEE SK: Insufficient sex description of cells supplied by commercial vendors. Am J Physiol Cell Physiol 308: C578-C580, 2015. https://doi.org/10.1152/ajpcell.00396.2014

PENALOZA C, ESTEVEZ B, ORLANSKI S, SIKORSKA M, WALKER R, SMITH C, SMITH B, LOCKSHIN RA, ZAKERI Z: Sex of the cell dictates its response: differential gene expression and sensitivity to cell death inducing stress in male and female cells. FASEB J 23: 1869-1879, 2009. https://doi.org/10.1096/fj.08-119388

PESSIN J, MARTS SA: Sex, gender, drugs, and the brain. Endocrinology 146: 1649, 2005. https://doi.org/10.1210/en.2005-0198

PHILLIPS NLH, ROTH TL: Animal models and their contribution to our understanding of the relationship between environments, epigenetic modifications, and behavior. Genes 10: 47, 2019. https://doi.org/10.3390/genes10010047

PLEVKOVA J, BUDAY T, KAVALCIKOVA-BOGDANOVA N, KOVACIKOVA L, RUZINAK R: Role of gender in basic cough research. Respir Physiol Neurobiol 245: 53-56, 2017a. https://doi.org/10.1016/j.resp.2016.12.006

PLEVKOVA J, BUDAY T, KAVALCIKOVA-BOGDANOVA N, IOAN I, DEMOULIN-ALEXIKOVA S: Sex differences in cough reflex. Respir Physiol Neurobiol 245: 122-129, $2017 \mathrm{~b}$. https://doi.org/10.1016/j.resp.2016.12.001

PRENDERGAST BJ, NELSON RJ, ZUCKER I: Mammalian seasonal rhythms: Behavior and neuroendocrine substrates. In: Hormones, Brain and Behavior. PFAFF DW, ARNOLD AP, FAHRBACH SE, ETGEN AM, RUBIN RT (eds), Elsevier, 2002, pp 93-156. https://doi.org/10.1016/B978-012532104-4/50021-4

RAHN EJ, IANNITTI T, DONAHUE RR, TAYLOR BK: Sex differences in a mouse model of multiple sclerosis: neuropathic pain behavior in females but not males and protection from neurological deficits during proestrus. Biol Sex Differ 5: 4, 2014. https://doi.org/10.1186/2042-6410-5-4

RICH-EDWARDS JW, KAISER UB, CHEN GL, MANSON JE, GOLDSTEIN J: Sex and gender differences research design for basic, clinical, and population studies: essentials for investigators. Endocr Rev 39: 424-439, 2018. https://doi.org/10.1210/er.2017-00246

SANDBERG K, JI H: Sex differences in primary hypertension. Biol Sex Differ 3: 7, 2012. https://doi.org/10.1186/2042-6410-3-7

SCHWARZ P, JORGENSEN NR, MOSEKILDE L, VESTERGAARD P: The evidence for efficacy of osteoporosis treatment in men with primary osteoporosis: a systematic review and meta-analysis of antiresorptive and anabolic treatment in men. J Osteoporos 2011: 259818, 2011. https://doi.org/10.4061/2011/259818

SECHZER JA, RABINOWITZ VC, DENMARK FL, MCGINN MF, WEEKS BM, WILKENS CL: Sex and gender bias in animal research and in clinical studies of cancer, cardiovascular disease, and depression. Ann N Y Acad Sci 736: 21-48, 1994. https://doi.org/10.1111/j.1749-6632.1994.tb12816.x

SHANSKY RM: Are hormones a "female problem" for animal research? Science 364: 825-826, 2019. https://doi.org/10.1126/science.aaw7570

SIMON TURNER A: Animal models of osteoporosis - necessity and limitations. Eur Cell Mater 1: 66-81, 2001. https://doi.org/10.22203/eCM.v001a08

SOLDIN OP, MATTISON DR: Sex differences in pharmacokinetics and pharmacodynamics. Clin Pharmacokinet 48: 143-157, 2009. https://doi.org/10.2165/00003088-200948030-00001

SONG W-J, CHANG Y-S, FARUQI S, KIM J-Y, KANG M-G, KIM S, JO E-J, KIM M-H, PLEVKOVA J, PARK H-W, CHO S-H, MORICE AH: The global epidemiology of chronic cough in adults: a systematic review and metaanalysis. Eur Respir J 45: 1479-1481, 2015. https://doi.org/10.1183/09031936.00218714 
STERUSKY M, PLEVKOVA J, GRENDAR M, BUDAY T: Female guinea pig model for cough studies and its response to most common tussive substances. Physiol Res 69 (Suppl 1): S171-S179, 2020. https://doi.org/10.33549/physiolres.934409

TAYLOR KE, VALLEJO-GIRALDO C, SCHAIBLE NS, ZAKERI R, MILLER VM: Reporting of sex as a variable in cardiovascular studies using cultured cells. Biol Sex Differ 2: 11, 2011. https://doi.org/10.1186/2042-6410-2$\underline{11}$

WALD C, WU C: Biomedical research. Of mice and women: the bias in animal models. Science 327: 1571-1572, 2010. https://doi.org/10.1126/science.327.5973.1571

WETHERINGTON CL: Sex-gender differences in drug abuse: a shift in the burden of proof? Exp Clin Psychopharmacol 15: 411-417, 2007. https://doi.org/10.1037/1064-1297.15.5.411

WILL TR, PROAÑO SB, THOMAS AM, KUNZ LM, THOMPSON KC, GINNARI LA, JONES CH, LUCAS S-C, REAVIS EM, DORRIS DM, MEITZEN J: Problems and progress regarding sex bias and omission in neuroscience research. eNeuro 4: ENEURO.0278-17.2017, 2017. https://doi.org/10.1523/ENEURO.0278$\underline{17.2017}$

WIZEMANN TM, PARDUE ML: Exploring the Biological Contributions to Human Health: Does Sex Matter? National Academy Press, Washington (DC), 2001, 288 p. https://doi.org/10.17226/10028

YANG X, SCHADT EE, WANG S, WANG H, ARNOLD AP, INGRAM-DRAKE L, DRAKE TA, LUSIS AJ: Tissuespecific expression and regulation of sexually dimorphic genes in mice. Genome Res 16: 995-1004, 2006. https://doi.org/10.1101/gr.5217506

YOON DY, MANSUKHANI NA, STUBBS VC, HELENOWSKI IB, WOODRUFF TK, KIBBE MR: Sex bias exists in basic science and translational surgical research. Surgery 156: 508-516, 2014. https://doi.org/10.1016/j.surg.2014.07.001

ZAKINIAEIZ Y, COSGROVE KP, POTENZA MN, MAZURE CM: Balance of the sexes: addressing sex differences in preclinical research. Yale J Biol Med 89: 255-259, 2016.

ZUCKER I, BEERY AK: Males still dominate animal studies. Nature 465: 690-690, 2010. https://doi.org/10.1038/465690a 